\title{
Naphthenic Corrosion Resistance, Mechanical Properties and Microstructure Evolution of Experimental Cr-Mo Steels with High Mo Content
}

\author{
Lorena Braga Moura ${ }^{\mathrm{a}}$, Rodrigo Freitas Guimarães ${ }^{\mathrm{a}}$, Hamilton Ferreira Gomes de Abre ${ }^{\mathrm{a} *}$, \\ Hélio Cordeiro de Miranda ${ }^{\mathrm{a}}$, Sérgio Souto Maior Tavares ${ }^{\mathrm{b}}$ \\ ${ }^{a}$ Departamento de Engenharia Metalúrgica e Materiais, Universidade Federal do Ceará - UFC, \\ Campus do Pici, Bloco 702, CEP 60455-760, Fortaleza, CE, Brazil \\ ${ }^{\mathrm{b}}$ Departamento de Engenharia Mecânica, Universidade Federal Fluminense - UFF, \\ Rua Passo da Pátria, 156, CEP 24210-240, Rio de Janeiro, RJ, Brazil
}

Received: August 10, 2011; Revised: January 23, 2012

\begin{abstract}
One method to face the effects of naphthenic acid corrosion in petroleun refining plants is to use alloys with good resistance to this kind of corrosion. For this purpose, molybdenum additions to chromium containing steels are specially recommended. In this work, experimental $\mathrm{Fe}-9 \mathrm{Cr}-\mathrm{xMo}$ $(\mathrm{x}=5,7$ and $9 \mathrm{wt} .(\%))$ ingots were cast, forged and hot rolled before being tested in a naphthenic acid environment. Evolution of the mechanical properties with composition is presented. The precipitation and dissolution of phases were investigated with the help of Thermocalc and electron backscattered diffraction (EBSD).
\end{abstract}

Keywords: FeCrMo, molybdenum, naphthenic corrosion

\section{Introduction}

Corrosion in crude heavy oil processing has become a major problem in the oil industry. Most oil plants have been designed and constructed to process oil with low levels of naphthenic acidity. Discovery of heavy oil reservoirs has transformed the processing of highly acidic oil into a major economic endeavor. Naphthenic corrosion is caused by carboxylic acid oxygenates. The two methods most frequently used to control naphthenic corrosion are blending with oils with low naphthenic acid content to dilute and reduce acidity to an acceptable level for a particular distillation unit and use of materials resistant to naphthenic corrosion. The most appropriate method depends on many factors such as economy, velocity, turbulence, temperature and concentration of acids ${ }^{1}$.

The presence of naphthenic acids and sulfur complexes considerably increases the corrosion of parts subjected to high temperatures during oil processing, typically higher than about $230{ }^{\circ} \mathrm{C}$. Two major areas are normally affected, distillation towers (atmospheric and vacuum) and piping circuits, including furnace tubes. According to reports from oil refineries, Mo-bearing stainless steels such as AISI 316 and AISI 317 are the preferred; low-carbon grades are usually specified to also resist wet corrosion during downtime periods. Increasing the Mo content increases naphthenic acid corrosion but a minimum of about 2.3 to $2.5 \%$ is indicated to be necessary. There are some works published in the literature that agree with this statement and also specify that the addition of Mo in the alloy considerably increases its resistance to naphthenic acid corrosion ${ }^{2-6}$.

*e-mail: hamilton@ufc.br
The use of austenitic stainless steels in distillation units in oil refineries poses its own problems of stress corrosion cracking due to either chlorides during operation and downtime or polythionic acids during down time ${ }^{7}$. An alternative would be to use ferritic stainless steels that are not susceptible to these stress corrosion cracking mechanisms, with an addition of Mo, to make them resistant to naphthenic acid corrosion.

Another application would be in the tubes inside the furnaces used for oil refining. The material of these tubes is usually $5 \mathrm{Cr} 0.5 \mathrm{Mo}$ or $9 \mathrm{Cr}-1 \mathrm{Mo}$ and they do not resist naphthenic acid corrosion. The choice of these steels is based on their resistance to sulfidation. Again, for this application, it would be attractive to refineries to use ferritic steel with a higher amount of Mo in its chemical composition to resist both sulfidation and naphthenic acid corrosion.

Mo stabilizes the chromium passive protective film, limiting naphthenic acid corrosion ${ }^{6}$. Molybdenum is a strong ferrite stabilizing element. Increasing the amount of molybdenum increases mechanical strength and hardness, and reduces toughness. When dealing with Fe-Cr-Mo steel, some deleterious phases could precipitate: sigma $(\sigma)$, chi $(\chi)$ and mu $(\mu)$ during service at high temperature. These phases may occur at temperatures between 600 and $900{ }^{\circ} \mathrm{C}$, their formation is usually slow, requiring several hours, days, months, or years depending on the exposed temperature. These phases are diffusional and are in equilibrium in a phase diagram, and therefore high cooling rates are required after welding or heat treatment to prevent the formation of these phases ${ }^{8-12}$. 
Rapid cooling keeps the allowing elements in solid solution but rapid cooling would normally harden some of the ferritic steels such as $5 \mathrm{Cr} 0.5 \mathrm{Mo}$ and $9 \mathrm{Cr} 1 \mathrm{Mo}$ steels. These steels are normally used in the normalized and tempered or in annealed condition.

$\sigma$ phase is an intermetallic compound of nominal composition $\mathrm{Fe}-\mathrm{Cr}$ and tetragonal unit cell, which is hard and nonmagnetic. The $\chi$ phase, in turn, has an ordered cubic structure, with composition $\mathrm{Fe}-25 \% \mathrm{Cr}$ - Ni $2 \%$ - 15-20\% Mo $-1 \%$ Mn. Both phases, $\chi$ and $\sigma$, cause embrittlement below about certain temperature and, in particular room temperature, and are undesirable in a steel. They reduce ductility and toughness. Phase $\mu$ has a hexagonal crystal structure, a nominal formula $\mathrm{Fe}_{7} \mathrm{Mo}_{6}$ and is a hard and brittle intermetallic compound. Phase $\mu$ is detrimental to materials, because its precipitation causes depletion of alloying elements in the matrix. In addition, its needle shape facilitates crack propagation ${ }^{13-17}$.

This work involved investigation of experimental ingots with $\mathrm{Cr}$ varying from 9 to $17 \%$ and Mo from 5 to $7 \%$. Aspects concerning resistance to naphthenic corrosion, mechanical properties, microstructure and kinetics of deleterious phases were analyzed. A detailed study of these experimental alloys using EBSD (electron backscattered diffraction) provided an understanding of the formation and dissolution of $\sigma, \mu$, and $\chi$ phases.

\section{Materials and Methods}

Ingots of $90 \mathrm{~kg}$, with chemical compositions shown in Table 1, were melted in an induction furnace. After casting, they were hot forged and hot rolled. The onset temperature for hot rolling ranged between 900 and $1000{ }^{\circ} \mathrm{C}$. The dimensions of plates after hot rolling were $200 \mathrm{~mm}$ wide and $12 \mathrm{~mm}$ thick. After hot rolling the alloys were solution annealing to dissolve alloying elements in the matrix homogeneously and to obtain uniform microstructure and properties. Samples were solution annealed for one hour at $1000{ }^{\circ} \mathrm{C}$ (alloys with $5 \%$ of Mo), $1060{ }^{\circ} \mathrm{C}$ (alloys with $7 \% \mathrm{Mo}$ ) and $1100{ }^{\circ} \mathrm{C}$ (alloys with $9 \% \mathrm{Mo}$ ) and then water quenched to room temperature.

Samples for naphthenic corrosion were fist machined followed by gridding. After that, all samples were sand blasted. Then, they were weighed on a precision balance (0.1 mg). A reference weight 316 stainless steel was used during the weighing to minimize errors during this procedure.

Table 1. Chemical composition (in weight percent) of the alloys.

\begin{tabular}{cccccc}
\hline Alloy & C & Mn & Si & Cr & Mo \\
\hline 9Cr5Mo & 0.030 & 0.37 & 0.34 & 9.5 & 5.3 \\
9Cr7Mo & 0.031 & 0.38 & 0.37 & 9.5 & 7.3 \\
9Cr9Mo & 0.041 & 0.41 & 0.45 & 9.6 & 9.3 \\
11Cr9Mo & 0.039 & 0.38 & 0.38 & 11.1 & 9.2 \\
13Cr5Mo & 0.037 & 0.38 & 0.36 & 13.1 & 5.0 \\
13Cr9Mo & 0.032 & 0.34 & 0.42 & 13.2 & 9.0 \\
17Cr5Mo & 0.025 & 0.40 & 0.41 & 16.9 & 5.1 \\
\hline
\end{tabular}

Naphthenic corrosion tests were carried out in an autoclave (pressure of $30 \mathrm{lb} / \mathrm{in}^{2}$ or psig) and temperature of $340^{\circ} \mathrm{C}$. Inside the autoclave was installed a rotating carousel where the specimens were fixed and rotated at $1500 \mathrm{rpm}$. The corrosive media was crude petroleum with high level of acidity (2.5 mg KOH.g-1). The uniform corrosion rates were determined according to ASTM ${ }^{\circledR} \mathrm{G} 1$, with immersion cycles of 30 seconds, using Clark's solution for different compositions of Fe-Cr-Mo alloys. Samples of three commercial alloys, AISI 1020, AISI 316 and 9Cr1Mo, were placed in the autoclave in the same run of the experiment to be used as references.

Thermodynamic calculations had been done to determine possible phases that precipitate in the material. Thermo-Calc software and the TC-FE6 were used. ThermoCalc is a software package that performs thermodynamic and phase diagrams calculations for multi-component systems. TC-FE6 is a database developed for Steel and Fe-alloys.

Tension tests were done at room temperature in an Instron 8802 tester according to ASTM ${ }^{\circledR}$ E8-03 standards. All tests were performed in samples annealed after hot rolling. Square cross section specimens were machined aligning the length of the specimen with the rolling direction of the sheet. Charpy impact experiments to determine absorbed energy and the fracture surface appearance were conducted according to ASTM ${ }^{\circledR}$ E23-07. Specimens of reduced size $(5 \times 10 \times 55 \mathrm{~mm})$ were machined with a v-notch parallel to the rolling direction.

Specimens for light optical microscopy (LOM) were prepared by a standard method including grinding, polishing and etching.

EBSD data was acquired in an Oxford Crystal 300 system attached to a SEM Philips XL-30. Channel-5 software from HKL was used for processing. The metallographic specimen were polished using colloidal silica for 30 minutes, and the EBSD measurements were performed on a SEM working with a tungsten filament electron gun operating at an acceleration voltage of $25 \mathrm{kV}$. The EBSD orientation maps have been acquired with a step size of $900 \mathrm{~nm}$ and by assuming the presence of four possible crystallographic phases: Fe-BCC for ferrite, $\mathrm{Cr}_{6} \mathrm{Fe}_{18} \mathrm{Mo}$ $\left(\chi\right.$-phase), $\mathrm{Cr}-\mathrm{Fe}$ ( $\sigma$ phase) and $\mathrm{Fe}_{7} \mathrm{Mo}_{6}(\mu$ phase).

\section{Results}

\subsection{Naphthenic acid corrosion resistance}

Six different compositions of FeCrMo alloys, AISI 316 austenitic stainless steel, 9Cr-1Mo steel and AISI 1020 low carbon steel were selected to perform preliminary tests of naphthenic corrosion.

Figure 1 summarizes the naphthenic acid corrosion mass loss per year for six different FeCrMo alloys along with 9Cr1Mo, AISI 1020 steel and AISI 316 austenitic stainless steel. This is referred to as corrosion rate.

Increasing the Mo content from 1 to $5 \%$ in alloys with $9 \%$ of chromium resulted in a reduction of corrosion rate. However, a further increase to 9 Mo to $9 \% \mathrm{Cr}$ steel did not further improve the corrosion resistance to this testing medium. The chromium content influenced the naphthenic 
acid corrosion resistance, as illustrated. Further addition of Mo to $9 \mathrm{Cr}$ steel resulted in some additional reduction of the rate of corrosion. Increasing the molybdenum content from 5 to $9 \%$ in alloys with 13 and $9 \%$ of chromium did not appear to exert a significant influence on the corrosion rates by the action of naphthenic acids. This contrasts the general belief that chromium addition increases the corrosion resistance to sulfidation but does very little contribution to increase the resistance to naphthenic acid corrosion.

\subsection{Mechanical properties}

Mechanical properties of Cr-Mo steels vary greatly depending on the thermal history. Comparison is thus valid only if they have similar heat treatment conditions. The results of tensile tests on alloys $17 \mathrm{Cr} 5 \mathrm{Mo}, 15 \mathrm{Cr} 5 \mathrm{Mo}$, 9Cr5Mo, 9Cr7Mo and 9Cr9Mo in the annealed condition are shown in Figures 2a,b. Comparing values for yield and ultimate tensile stress of alloys $17 \mathrm{Cr} 5 \mathrm{Mo}$ and $15 \mathrm{Cr} 5 \mathrm{Mo}$ (ferritic stainless steel) with the commercial alloy K44

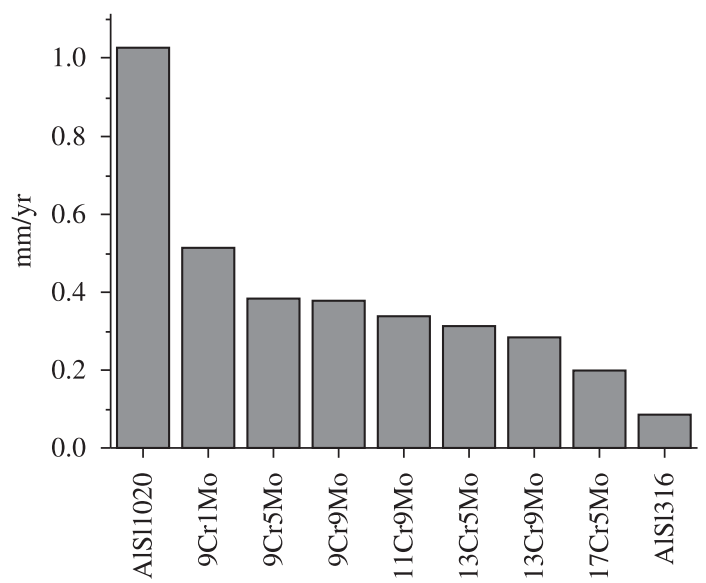

Figure 1. Mass loss of different materials tested in an autoclave in liquid phase.

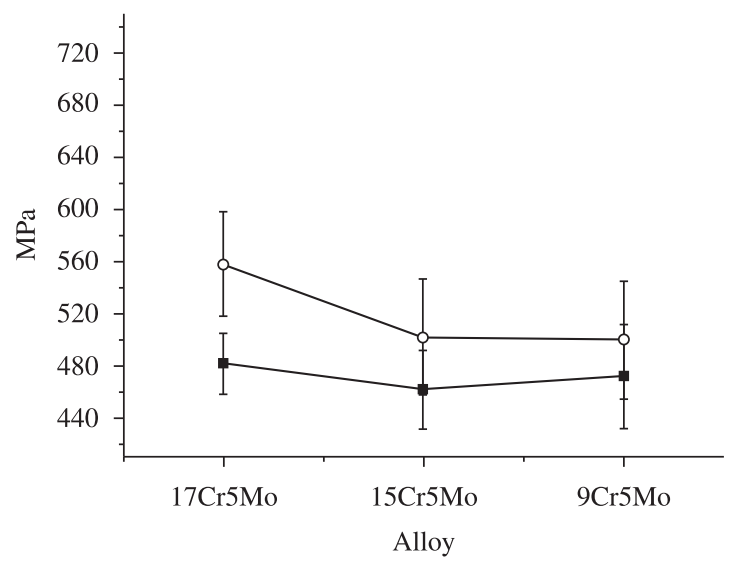

(a)
(AISI $444-18 \% \mathrm{Cr}$ and $1.8 \% \mathrm{Mo}$ ) from Arcelor Mittal in the annealed condition, can be concluded that the experimental alloys have higher yield strength, 483.8 and $461.7 \mathrm{MPa}$ against $380 \mathrm{MPa}$ for alloy K44.

The variation in chromium content did not result in a significant change within the limits of yielding stress and ultimate tensile strength among the alloys $17 \mathrm{Cr} 5 \mathrm{Mo}$, $15 \mathrm{Cr} 5 \mathrm{Mo}$ and $9 \mathrm{Cr} 5 \mathrm{Mo}$. On the other hand, the increase of Mo produces a large increase in yielding and ultimate stress in alloy 9Cr5Mo, 9Cr7Mo and 9Cr9Mo (Figure 2b). Molybdenum content presents a more relevant effect on mechanical properties than chromium.

Another aspect to analyze is toughness. Figures 3a,b show the values of energy absorbed in a Charpy- $\mathrm{V}$ reduced impact testing at $22{ }^{\circ} \mathrm{C}$ (room temperature), and at $60{ }^{\circ} \mathrm{C}$, in specimens obtained from the alloys $17 \mathrm{Cr} 5 \mathrm{Mo}, 15 \mathrm{Cr} 5 \mathrm{Mo}$ 9Cr5Mo, 9Cr7 Mo and 9Cr9Mo. As can be seen, regardless of the levels of chromium and molybdenum, no significant changes were observed in the values of absorbed energy at room temperature. The low values of absorbed energy obtained and appearance of the observed fractures after the Charpy-V impact test indicated that $20^{\circ} \mathrm{C}$ was below the transition temperature for these alloys where they exhibit a brittle-like behavior. However, increasing the test temperature to $60{ }^{\circ} \mathrm{C}$ a considerable increase in placed these alloys above their ductile-brittle transition temperature as shown by a considerable increase in the corresponding absorbed energy. Tests at $60{ }^{\circ} \mathrm{C}$ showed that increasing the $\mathrm{Cr}$ and Mo content resulted in decreasing of toughness of these alloys. According to these experiments, Mo has a greater influence on toughness than $\mathrm{Cr}$. Figure 4 presents the appearance of the fracture after Charpy-V tests. The bright aspect of fractured surfaces is characteristic of brittle fracture type.

The determination of the amount of sheared surface was made in accordance to ASTM E 23 standard by measuring length and width of flat fracture region. Table 2 presents the results for shear percent for each composition at 25 and $60{ }^{\circ} \mathrm{C}$

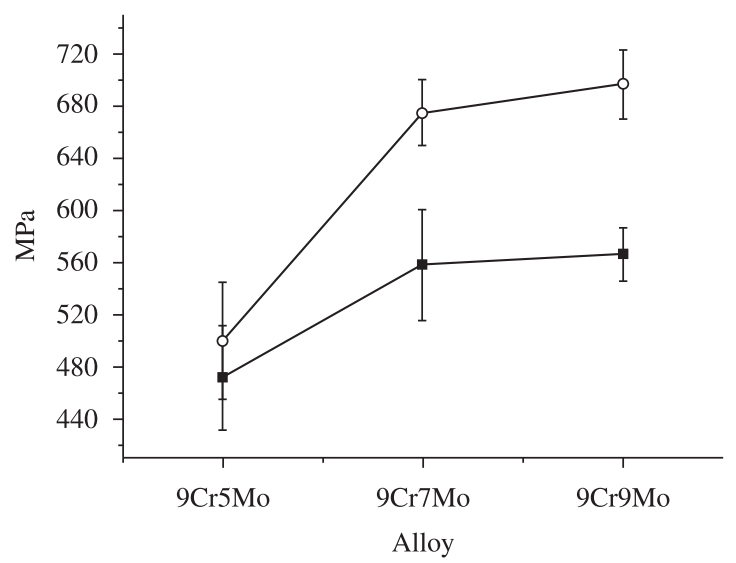

(b)

Figure 2. Yielding stress and ultimate stress for alloys with different amounts of $\mathrm{Cr}$ (a) and different amounts of $\mathrm{Mo}$ (b). 


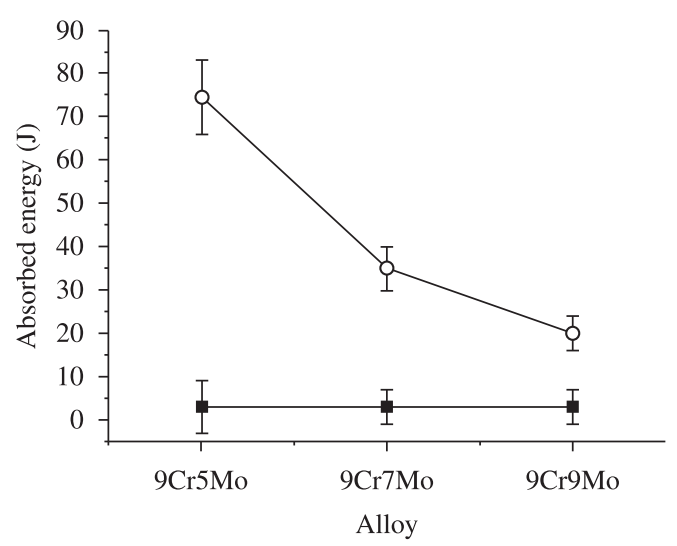

(a)

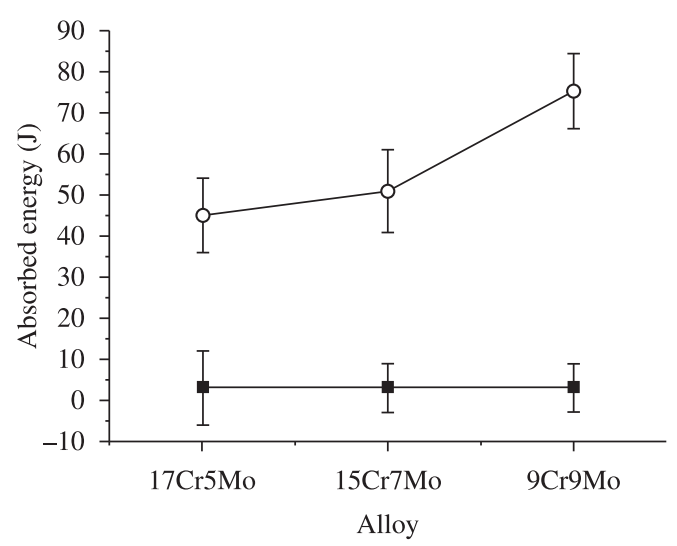

(b)

$\rightarrow 22^{\circ} \mathrm{C} \quad-60^{\circ} \mathrm{C}$

Figure 3. Absorbed energy after Charpy impact test at temperatures of 22 and $60{ }^{\circ} \mathrm{C}$; a) Change in the $\mathrm{Cr}$ content; b) Change in Mo content.

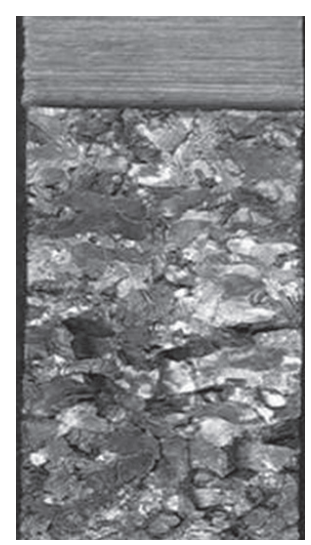

(a)

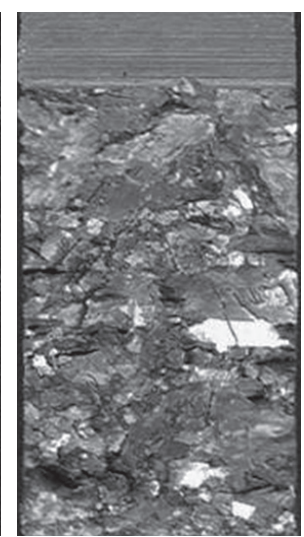

(b)

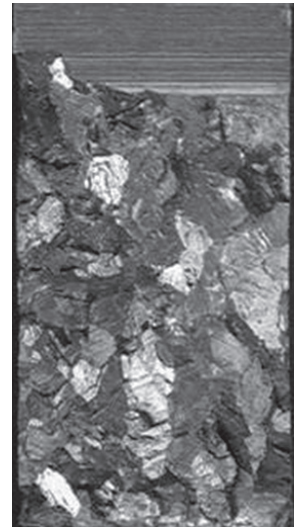

(c)

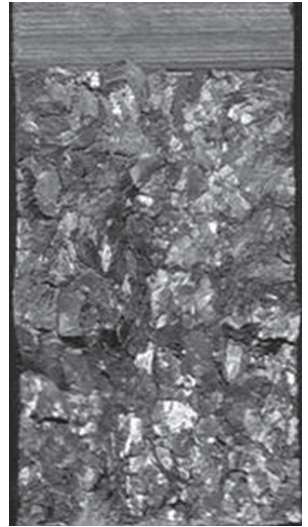

(d)

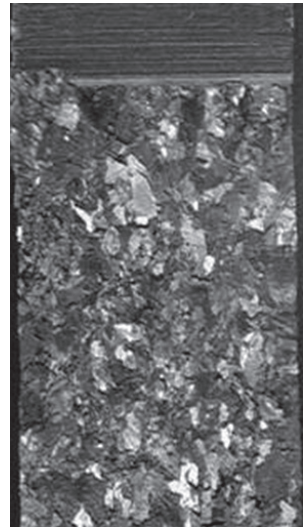

(e)

Figure 4. Appearance of the fracture of Charpy-V specimens $\left(2{ }^{\circ} \mathrm{C}\right)$; a) $(17 \mathrm{Cr} 5 \mathrm{Mo})$; b) $(15 \mathrm{Cr} 5 \mathrm{Mo})$; c) $(9 \mathrm{Cr} 5 \mathrm{Mo})$; d) (9Cr7Mo); e) $(9 \mathrm{Cr} 9 \mathrm{Mo})$.

Table 2. Percent shear for fracture surfaces presented on Figures 4 and 5.

\begin{tabular}{ccc}
\hline Alloy & T $\left({ }^{\circ} \mathbf{C}\right)$ & \% shear \\
\hline \multirow{2}{*}{9 Cr5Mo } & 25 & 20 \\
& 60 & 90 \\
\multirow{2}{*}{9 Cr7Mo } & 25 & 20 \\
& 60 & 80 \\
\multirow{2}{*}{9 Cr9Mo } & 25 & 20 \\
& 60 & 20 \\
\multirow{2}{*}{$15 \mathrm{Cr} 5 \mathrm{Mo}$} & 25 & 20 \\
& 60 & 80 \\
17Cr5Mo & 25 & 20 \\
& 60 & 70 \\
\hline
\end{tabular}

\subsection{Thermodynamic simulations}

Thermo-Calc is a tool that makes possible to predict phases at equilibrium and metastable equilibrium conditions based on the composition of the system, temperature and pressure. Thermodynamic modeling of the alloys was
Table 3. Effect of Mo content on the austenite phase stability field in the $\mathrm{Fe}-\mathrm{Cr}$ phase diagram.

\begin{tabular}{cccc}
\hline \% Mo & $\begin{array}{c}\text { Lower limit of } \\
\text { the austenite } \\
\text { phase }\left({ }^{\circ} \mathbf{C}\right)\end{array}$ & $\begin{array}{c}\text { Upper limit of } \\
\text { the austenite } \\
\text { phase }\left({ }^{\circ} \mathbf{C}\right)\end{array}$ & $\begin{array}{c}\text { Solubility limit } \\
\text { of Cr in the } \\
\text { austenite phase }\end{array}$ \\
\hline 0 & 853 & 1394 & 13.5 \\
1 & 880 & 1356 & 11.5 \\
2 & 916 & 1311 & 9.5 \\
2.4 & 934 & 1290 & 8.6 \\
$>5$ &
\end{tabular}

performed using the program TCW5 and database TCFE6. The chemical composition presented in Table 1 was used in modeling. Increasing the molybdenum content causes a reduction in the austenite field (Iron- $\gamma$ ), also causes an increase in the lower limit of austenite and a lower and upper limit of solubility of chromium in the austenite ( $\gamma$-iron) to a maximum of $2.4 \%$ molybdenum (Table 3 ), when the austenitic field no longer exists. All compositions 


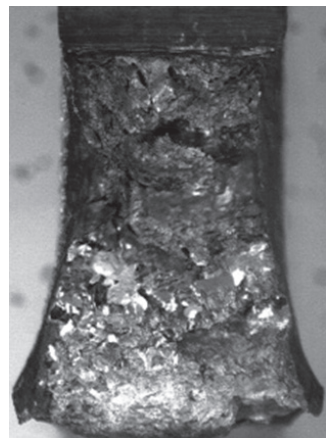

(a)

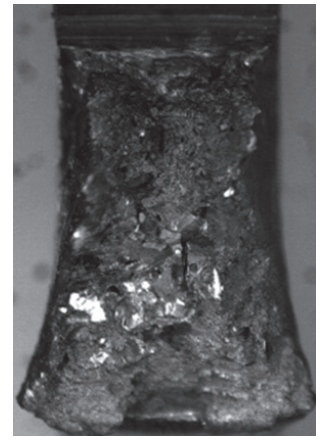

(b)

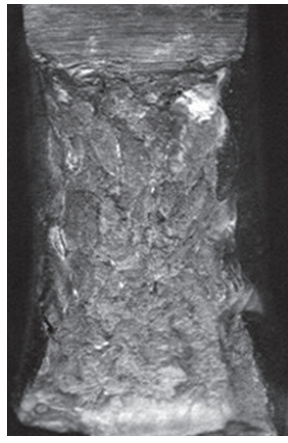

(c)

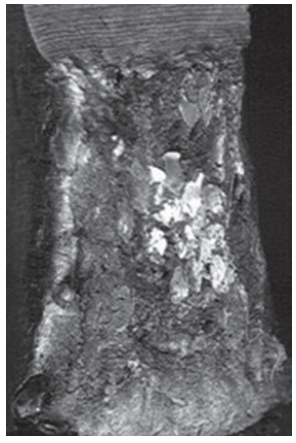

(d)

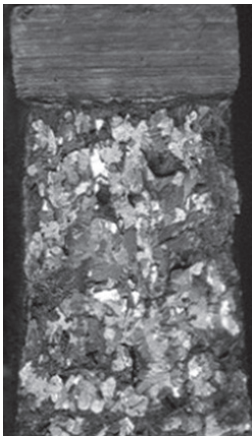

(e)

Figure 5. Appearance of the fracture of Charpy-V specimens $\left(60{ }^{\circ} \mathrm{C}\right)$; a) $(17 \mathrm{Cr} 5 \mathrm{Mo})$; b) $(15 \mathrm{Cr} 5 \mathrm{Mo})$; c) $(9 \mathrm{Cr} 5 \mathrm{Mo})$; d $)(9 \mathrm{Cr} 7 \mathrm{Mo})$; e) $(9 \mathrm{Cr} 9 \mathrm{Mo})$.

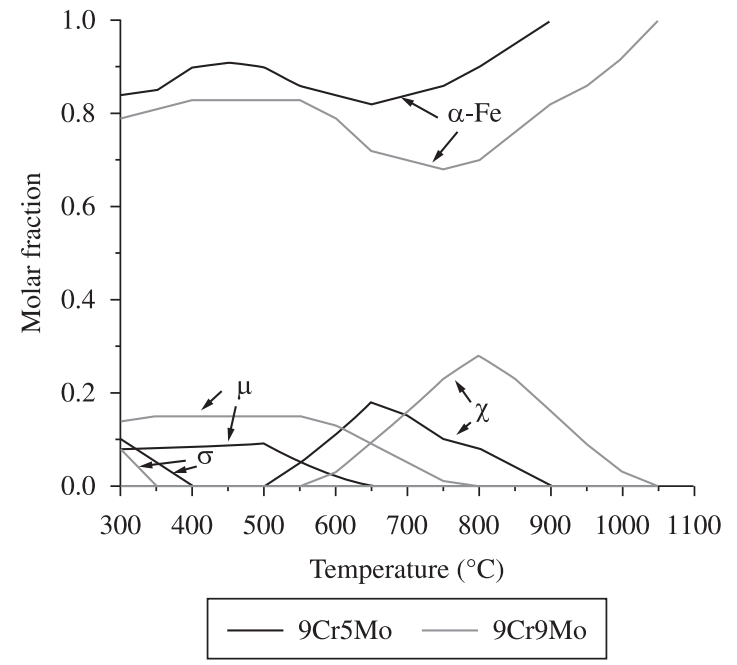

Figure 6. Weight fraction of $\alpha-\mathrm{Fe}, \sigma, \chi$ and $\mu$ in the alloys $9 \mathrm{Cr} 5 \mathrm{Mo}$ and $9 \mathrm{Cr} 9 \mathrm{Mo}$.

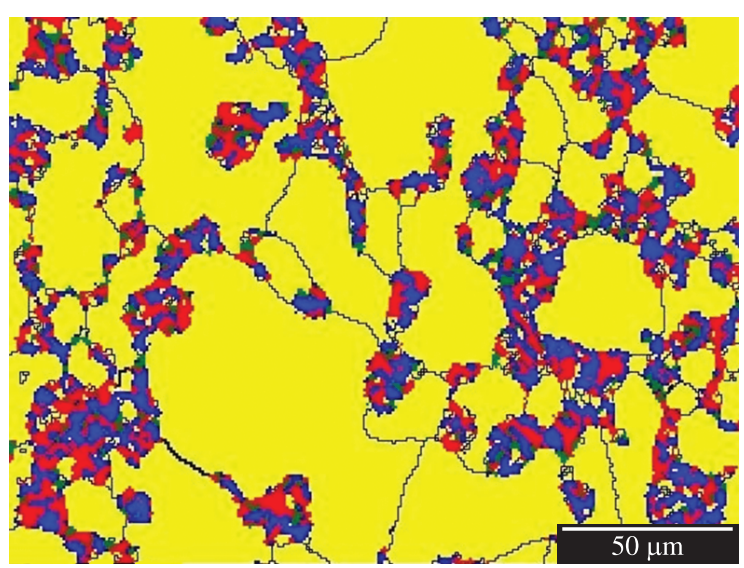

Figure 7. EBSD map of phases for the alloy Fe9Cr9Mohot rolled at $1000{ }^{\circ} \mathrm{C}$ and cooled in air: Ferrite (yellow), $\sigma$ (red), $\chi$ (green) and $\mu$ (blue).

presented in Table 1 when heated from room temperature to liquid phase temperature do not precipitate austenite. They precipitate ferrite (Iron- $\alpha$ ), $\sigma, \chi$ and $\mu$. Figure 6 shows the variation of the weight fraction of the ferrite phase and deleterious phases $\sigma, \chi$ and $\mu$ in the alloys $9 \mathrm{Cr} 5 \mathrm{Mo}$ and $9 \mathrm{Cr} 9 \mathrm{Mo}$ when these alloys were heated from room temperature to liquid phase temperature. The sigma phase in alloy $9 \mathrm{Cr} 5 \mathrm{Mo}$ is transformed into ferrite up to $400{ }^{\circ} \mathrm{C}$; the amount of $\mu$ phase remains constant up to $500{ }^{\circ} \mathrm{C}$, at which point it starts the precipitation of the $\chi$ phase. The $\chi$ phase reaches the maximum volume fraction at $650{ }^{\circ} \mathrm{C}$, when it starts its dissolution into ferrite. At $900{ }^{\circ} \mathrm{C}$ this alloy is ferrite-BCC. The alloy with $9 \%$ Mo follows a similar pattern, showing differences in the volume fractions of phases and the temperatures at which transformations occur. Complete dissolution of all these alloys occurs above $1050{ }^{\circ} \mathrm{C}$, when the alloy is $100 \%$ ferrite.

\subsection{Microstructure}

Phase identification and the mechanism of dissolution of these phases can be seen on images obtained by EBSD. Figure 7 shows a map of phases of a sample of alloy $9 \mathrm{Cr} 9 \mathrm{Mo}$ hot rolled atan initial temperature above $1100{ }^{\circ} \mathrm{C}$ and cooled in air. The figure shows the presence of phases $\sigma$ (red), $\mu$ (blue) and $\chi$ (green) at the ferrite (yellow) grain boundary. The phase map also reveals that these phases are concentrated at triple boundary junctions. Several researchers have observed this characteristic in the precipitation of the sigma phase in superferritic stainless steels ${ }^{18-20}$

The $\chi$ phase is present in small quantities inside the mu and sigma phases (see green areas in Figure 7), and influences the formation of these later phases. Phases $\chi$ and $\mu$ are favored by the presence of molybdenum. The kinetics of the phases is related to temperature and exposure time. According to Park et al. ${ }^{18}$, the $\sigma$ phase dissolves first, favoring the growth of $\mu$ and $\chi$ phases that continue to exist at higher temperatures. This behavior is in perfect agreement with the calculated amounts of the phases with Thermocalc shown in Figure 6.

Figure 8 shows orientation and phase maps for samples of the alloy $9 \mathrm{Cr} 7 \mathrm{Mo}$ annealed at $1060{ }^{\circ} \mathrm{C}$ for 10 minutes and one hour and cooling in air. As shown in Figure 8a (map of phase), $\chi, \mu$ and $\sigma$ phases have dissolved and the alloy became $100 \% \alpha$-BCC. The intermetallic phases surrounding ferritic grains that existed prior to annealing dissolves in the ferritic matrix after 10 minutes trial. The grain boundary 


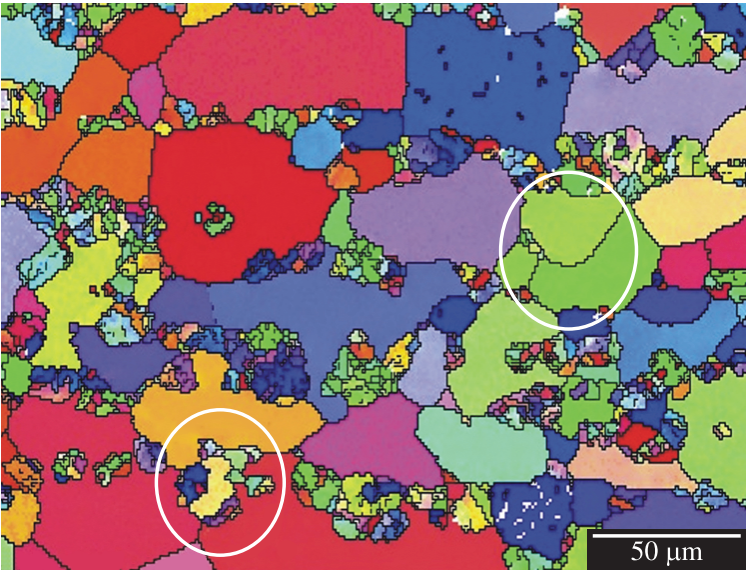

(a)

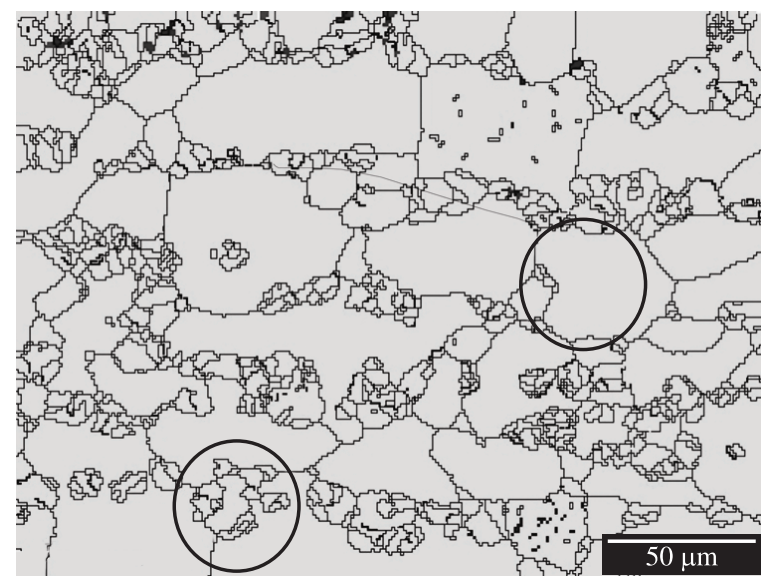

(c)

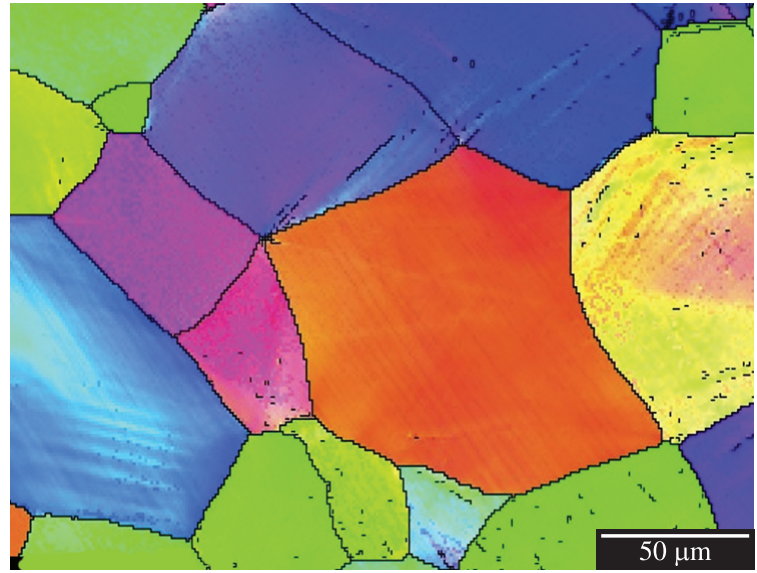

(b)

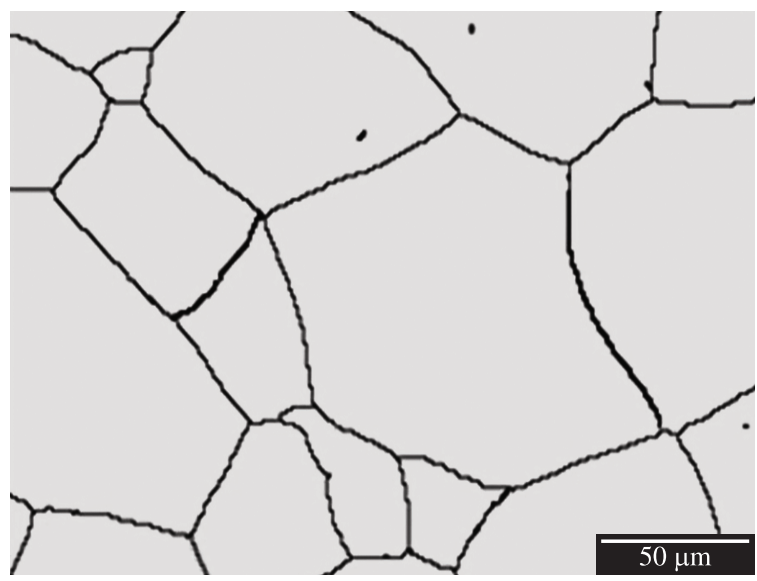

(d)

Figure 8. a) Orientation map for specimen annealed for 10 minutes; b) orientation map for specimen annealed for 1 hour; c) phase map for sample annealed for 10 minutes; d) phase map for sample annealed for 1 hour.

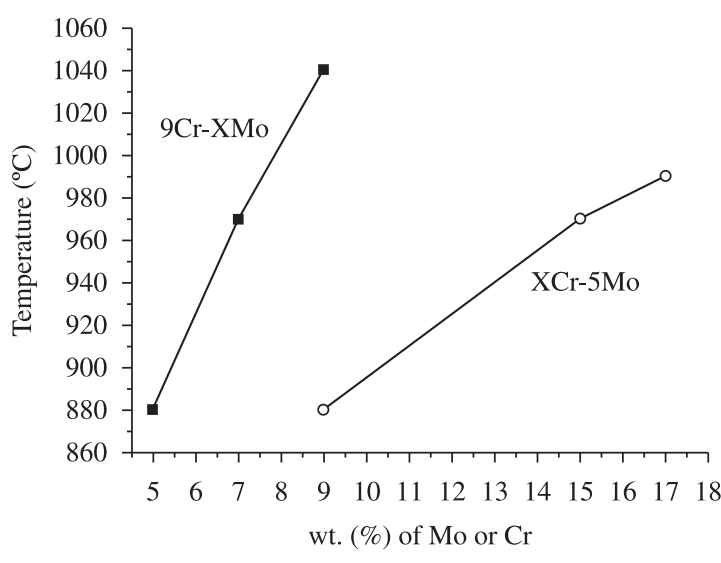

Figure 9. Experimental results for the temperature of solution annealing of a set of compositions of Fe-Cr-Mo.

regions in the ferritic matrix are now occupied by small grains of $\alpha$-ferrite. With increasing annealing time, the crystallographic orientations of these grains will change tending to the orientation of the ferritic grain that surrounds them. The small ferrite grains are acquiring new orientations aligning with larger grains as indicated by the colors on the phase map in Figure $8 \mathrm{~b}$. Notice in the region marked by a circle on the right of Figure $8 \mathrm{~b}$ that the grains present different shades of green, indicating the trend to form a larger grain with the same orientation. This process of reorientation of low angles grain boundaries and its subsequent grain growth during the transformation of the ferritic matrix is similar to the nucleation process during recrystallization. As subgrains are formed, they are able to grow on their neighbors by migrating sub-boundaries with the help of temperature. The subgrain absorbs dislocations in migration, decreasing the difference in orientation, its energy and its mobility until it becomes part of a larger grain ${ }^{21}$.

Another model observed during the test is known as nucleation by coalescence of subgrains. This mechanism is the coalescence of two neighboring subgrains equivalent to one rotation, making their crystalline lattices coincident. The coarsening of subgrains promotes grain growth, elimination of subgrains (decreasing the energy stored) and changes of orientation differences between the group affected by the subgrain coalescence and neighbors, which leads to 


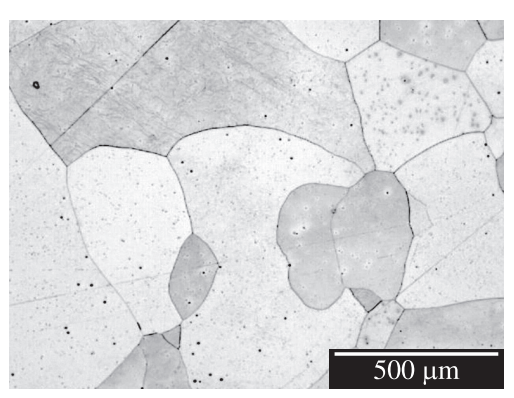

(a)

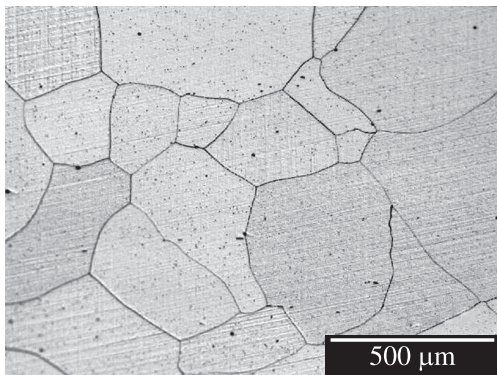

(b)

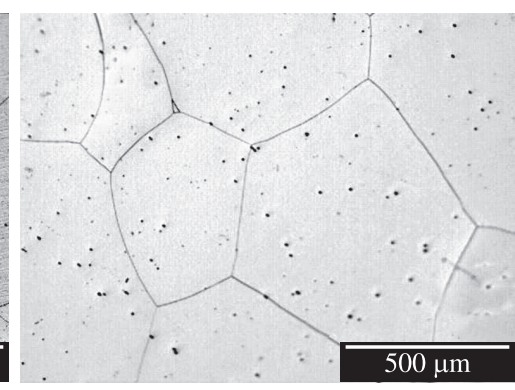

(c)

Figure 10. Microstructure of the alloy with $9 \% \mathrm{Cr}$ : a) $5 \% \mathrm{Mo}$; b) $7 \% \mathrm{Mo}$; and c) $9 \%$ Mo.

the appearance of a high-angle boundary able to move at high speed ${ }^{21}$.

When the dissolution process is complete, all intermetallic phases are dissolved, resulting in a ferrite matrix with welldefined grain boundaries and grain orientations without the presence of any precipitation between grain boundaries. This is clearly shown in Figures 8c,d, respectively phase map and orientation map after 1 hour of annealing.

Figure 9 shows the experimental solution annealing temperatures for alloys with $9 \% \mathrm{Cr}$ and $\mathrm{Mo} \mathrm{5,7}$ and 9\% (blue curve) and alloys with 5\% $\mathrm{Mo}$ and $\mathrm{Cr}-9,15$ and $17 \%$ (red curve). Above these temperatures only $\alpha$-BCC is present in the microstructure. Figure 9 shows that the increase of the amount of Mo has a greater effect on solution annealing temperature than increasing the amount of $\mathrm{Cr}$.

Higher solution annealing temperature results in an increase in grain size. Larger grains reduce ductility and are also one of the factors responsible for increasing of ductile-brittle transition temperature of ferritic alloys. Figure 10 shows the microstructure of the alloy with $9 \% \mathrm{Cr}$ and 5, 7 and $9 \%$ of Mo, respectively. The alloy $9 \mathrm{Cr} 5 \mathrm{Mo}$ was solution annealed at a temperature of $1000{ }^{\circ} \mathrm{C}$; $9 \mathrm{Cr} 7 \mathrm{Mo}$ at $1060{ }^{\circ} \mathrm{C}$; and $9 \mathrm{Cr} 9 \mathrm{Mo}$ at $1100{ }^{\circ} \mathrm{C}$, resulting in very large grains.

It should be noted that these alloys were produced as very low-carbon alloys. Many researchers have observed that carbon in a solution slows the kinetics of recrystallization in iron due to the segregation of carbon in the grain boundaries, reducing grain growth ${ }^{22}$. In steels, small amounts of elements such as $\mathrm{Al}, \mathrm{V}, \mathrm{Ti}$ and $\mathrm{Nb}$ are traditionally used, to control grain refinement at high temperature or during recrystallization ${ }^{22,23}$. These are examples of actions that can improve grain size in a future study of these alloys.

\section{Conclusions}

In this study, $\mathrm{Fe}-\mathrm{Cr}-\mathrm{Mo}$ alloys with levels of 9 to $17 \% \mathrm{Cr}$ and 5, 7 and 9\% Mo were analyzed. The results allow the following conclusions:

- Molybdenum content exceeding $5 \%$ by weight, besides leading to a series of metallurgical difficulties, does not promote improvements in the naphthenic corrosion resistance in crude petroleum with high level of acidity (2.5 mg KOH.g-1) in the alloys studied.

- Increasing the level of chromium improved the naphthenic corrosion resistance in crude petroleum with high level of acidity (2.5 mg KOH.g-1) for alloys with 9 and $5 \%$ Mo.

- The studied alloys showed a high yield strength and tensile strength, but low values of elongation.

- At room temperature $\left(25^{\circ} \mathrm{C}\right)$ alloys showed low values of energy absorbed, and brittle-like behavior. They exhibit ductile-like behavior for temperatures above $60^{\circ} \mathrm{C}$.

- Despite high levels of molybdenum favoring the formation of phases that are harmful to mechanical properties, it was possible to obtain microstructures without the presence of these phases through an adequate annealing.

- The percentage of $\sigma$ phase does not change significantly with the increase of Mo content. $\mu$ and $\chi$ phases increase with the increase of the Mo content in the alloy. Increasing Mo content also increases the solution annealing temperature of the alloys causing large grain sizes in samples with $9 \%$ Mo.

- After dissolution of $\sigma, \chi$ and $\mu$ phases, a recrystallization process occurs with mechanisms of nucleation by coalescence of subgrains and reorientation of low angle grain boundaries. 


\section{References}

1. Craig HL. Naphthenic acid corrosion in the refinery. In: Proceedings of the NACE Corrosion/95; 1995; Orlando, USA. Houston: NACE International; 1995. Paper n. 333.

2. Zetlmeisl MJ. Naphthenic Acid Corrosion and its Control. In: Proceedings of the Corrosion'96; 1996. Houston: NACE International; 1996. Paper n. 218.

3. Wu XQ, Jing HM, Zheng YG, Yao ZM and Ke W. Resistance of Mo-bearing stainless steels and Mo-bearing stainless-steel coating to naphthenic acid corrosion and erosion-corrosion. Corrosion Science. 2004; 46:1013. http://dx.doi.org/10.1016/ S0010-938X(03)00192-6

4. Vasconcelos IF, Tavares SSM, Reis FEU and Abreu HFG. Ageing effects on $\alpha^{\prime}$ precipitation and resistance to corrosion of a novel Cr-Mo stainless steel with high Mo content. Journal of Materials Science. 2009; 44:293-299. http://dx.doi. org/10.1007/s10853-008-3064-5

5. Negreiros YS, Herculano LFG, Lima-Neto P, Araujo WS, Guimarães RF and Abreu, HFG. Efeito do Teor de Mo na resistência a corrosão de ligas Fe-Cr-Mo. In: Anais do 18th Congresso Brasileiro de Engenharia e Ciência dos Materiais - CBECIMa; 2008; Porto de Galinhas, Brasil. Porto de Galinhas; 2008.

6. Gallo $\mathrm{G}$ and Edmondson J. The Effect of Molybdenum on Stainless Steels and Naphthenic Acid Corrosion Resistance. In: Proceedings of the Corrosion; 2008; New Orleans. Houston: NACE International; 2008.

7. Nace International Corporate. NACE Standard RP0179: Protection of Austenitic Stainless Steels and Other Austenitic Alloys from Polythionic Acid Stress Corrosion Cracking During Shutdown of Refinery Equipment. NACE.

8. Reis FEU. Influence of Mo content in $\mathrm{Fe}-\mathrm{Cr}$ alloys. [Dissertation] Fortaleza: Universidade Federal do Ceará; 2007.

9. 9 Guimarães RF, Figueredo NC, Pinheiro VM, Miranda HC and Abreu HFG. Influência do teor de Mo na Microestrutura de ligas Fe-9Cr-xMo. Soldagem e Inspeção. 2010; 15:25264.

10. Laffler B. Stainless - Stainless Steel and their Properties. 1999. p.1-44.

11. Edström HJ and Ljundberg L. Rost- und säurebeständige Chrom-Nickel- Stähle mit max. 0,030\% Kohlenstoff als
Kontruktionsmaterial für die chemische Industrie. Werkstoffe und Korrosion. 1964; 15:743-753.

12. Fontana MG. Corrosion Engineering. Cingapura: McGrawHill; 1986.

13. Khatak HS and Raj B. Corrosion of Austenitic Stainless Steel: Mechanism, Mitigation and Monitoring. Woodhead publishing; 2010. p. 1-36.

14. Link MS and Marshall PW. The formation of sigma phase in 13 to $16 \%$ chromium steels. Transactions of America Society for Metals. 1952; 44:549-565.

15. Sedricks AJ. Corrosion of Stainless Steels. 2th ed. New York: Wiley-Interscience Publications; 1996.

16. Pecker D and Bernstein IM. Handbook of stainless steels. New York: McGraw-Hill; 1977. p. 5-5, 5-7.

17. Durand-Charre M. Microestructure of steels and cast Irons. New York: Springer; 2004. 419 p.

18. Park CJ, Ahn MK and Know HS. Influence of Mo substitution by $\mathrm{W}$ on the precipitation kinetics of secundary phases and the associated localized corrosion and embrittlement in $29 \% \mathrm{Cr}$ ferrite stainless steels. Materials Science and Engineering. 2006; 418(1-2):211-217. http://dx.doi. org/10.1016/j.msea.2005.11.053

19. Escriba DM, Materna-Morris E, Plaut RLandPadilha AF. Effect of molybdenum on the chemical composition of sigma phase in three types of stainless steels. Foz do Iguaçu, Paraná: 17-CBECIMat 302-067 (Brazilian Congress of Engineering and Materials Science); 2006. P. 5068-5079.

20. Andrade TF. Precipitation of laves phase in stainless steel superferritic $28 \% \mathrm{Cr}-4 \% \mathrm{Ni}-2 \% \mathrm{Mo}-\mathrm{Nb}$. [Dissertação]. São Paulo: Universidade de São Paulo, 2006.

21. Padilha AF and Siciliano Junior F. Work hardening, recrystallization, grain growth and texture. 3th ed. São Paulo: Association of Metallurgy and Materials; 2005. 232 p.

22. Mesquita RA and Barbosa CA. Effect of $\mathrm{Ti}, \mathrm{Nb}$ and $\mathrm{V}$ in the growth of austenite grain of steel for hot work tool. Technology in Metallurgy and Materials. 2005; 1(3):7-12.

23. 23 Eldridge MF and Cochrane RC. The influence of aluminium and silicon on transformation kinetics in low alloys steels. Material science. 1998; 284-286:217-224. 